Donnerstag, den 14. Mai 2015

\title{
Einladung zur Mitgliederversammlung der DRG am 14. Mai 2015
}

Zur ordentlichen Mitgliederversammlung der Deutschen Röntgengesellschaft, Gesellschaft für Medizinische Radiologie e.V. (DRG), am Donnerstag, den 14. Mai 2015, von 17:30 - 19:00 Uhr im Congress-Centrum-Hamburg (CCH) im Saal Werner, lädt der Vorstand die Mitglieder der DRG hiermit herzlich ein.

\begin{tabular}{|c|c|}
\hline \multicolumn{2}{|c|}{ Tagesordnung } \\
\hline TOP 1 & Begrüßung \\
\hline TOP 2 & Totengedenken \\
\hline TOP 3 & $\begin{array}{l}\text { Genehmigung des Protokolls der } \\
\text { Mitgliederversammlung vom } 29 . \\
\text { Mai } 2014 \text { (veröffentlicht im Jah- } \\
\text { resbericht 63, Januar 2015) }\end{array}$ \\
\hline TOP 4 & Bericht des Präsidenten \\
\hline TOP 5 & Bericht des Schatzmeisters \\
\hline TOP 6 & Bericht der Kassenprüfer \\
\hline TOP 7 & Entlastung des Vorstandes \\
\hline TOP 8 & Vorschläge für Ehrungen 2016 \\
\hline TOP 9 & Wahl der Kassenprüfer 2016 \\
\hline TOP 10 & $\begin{array}{l}\text { Wahl des Vorstandes für die } \\
\text { Amtsperiode Röntgenkongress } \\
\text { 2015-2017 }\end{array}$ \\
\hline TOP 11 & $\begin{array}{l}\text { Wahl des Präsidenten für die } \\
\text { Amtsperiode Röntgenkongress } \\
\text { 2017-2019 }\end{array}$ \\
\hline TOP 12 & $\begin{array}{l}\text { Wahl des Kongresspräsidenten } \\
2018\end{array}$ \\
\hline TOP 13 & $\begin{array}{l}\text { Einladung zum Röntgenkongress } \\
2016\end{array}$ \\
\hline TOP 14 & $\begin{array}{l}\text { Bericht der Akademie für Fort- } \\
\text { und Weiterbildung in der Radio- } \\
\text { logie }\end{array}$ \\
\hline TOP 15 & $\begin{array}{l}\text { Bericht der Vorsitzenden der Ver- } \\
\text { einigung Medizinisch-Technischer } \\
\text { Berufe in der DRG (VMTB) }\end{array}$ \\
\hline TOP 16 & Bericht des Justitiars der DRG \\
\hline TOP 17 & Verschiedenes \\
\hline
\end{tabular}

Die Einlasskontrolle erfolgt über den Kongressausweis. Entsprechend der Satzung der DRG können an der Mitgliederversammlung nur Mitglieder teilnehmen, de- ren Beitragskonto für 2015 ausgeglichen ist.

Im Namen des Vorstandes Prof. Dr. Norbert Hosten (Präsident) 